\title{
FEATURES OF IMAGE COMPREHENSION THROUGH SYMBOLS
}

\author{
Galina A. Ermakova ${ }^{1 \star}$, Marina P. Savirova ${ }^{2}$, Nadezhda I. Yakimova ${ }^{3}$ \\ ${ }^{1}$ Full Prof. Dr., I.N. Ulyanova Chuvash State University, RUSSIA, ermakil@yandex.ru \\ ${ }^{2}$ Assoc. Prof. Dr., I.N. Ulyanova Chuvash State University, RUSSIA, marina.savirova @yandex.ru \\ ${ }^{3}$ Assoc. Prof. Dr., I.N. Ulyanova Chuvash State University, RUSSIA, yakimovanadya@yandex.ru
}

\begin{abstract}
In modern conditions of personal development, aimed at self-learning, self-development, speech-thinking activity plays a special role as a component of the characteristics of a successful person. The main goal of literary education is to study the texts of works of art, to understand literature as an artistic reality, to develop on this basis the spiritual world of a person, his worldview, and to foster the need for systematic reading as a necessary part of continuous spiritual and moral improvement of the individual, and to develop his intellectual and emotional-volitional spheres.

As an artistic phenomenon, the Word lived in the minds of people as an independent image that embodies the centuries-old experience of the people, since at all times its philosophical idea of life was understood and perceived as a great social mission.

The article deals with the problem of understanding the image through symbols on the example Of $\mathrm{V}$. Rasputin's story "Women's conversation". In the disclosure of the main idea of the text, the meaning of semantic groups is discussed. The article presents a situation in which a student, independently comprehending new information through reflection, reflects on the preservation of the spiritual and moral values of his people.
\end{abstract}

Keywords: Symbol, artistic image, word sign,spiritual and moral values, semantic groups, idea.

\section{INTRODUCTION}

Modern and classical literature in the education system can be used as spaces that lead students to speechthinking activities and introduce them to the spiritual and moral values of their people.

One of the ways to comprehend the idea of the work, the call of the text, is the analysis of semantic groups [1], [2],[3].

In this story, in our opinion, the author represents the following main semantic groups: images of the world of the grandmother, representing the spiritual and moral values of the Russian people; images of the world of the granddaughter Vika, through which the writer shows the immaturity of the younger generation, their unwillingness to adequately meet life's difficulties. These semantic groups represent the opposition: the wisdom of adults - the moral immaturity of the younger generation. Through the artistic world of this story, the author raises the problem of transferring the spiritual and moral experience accumulated by adults to the younger generation.

Articles researchers [4], [5], [6], [7] it is also stated that the analysis of any text should start with a meaningful 
perception of the text, as well as to see the position of the artist, but it needs to be able to see the word in the text, to feel the inspiration of the writer, for he who creates something, creates it with the help of inspiration. In addition, it is necessary to see the very word that is mentioned in the entire text, to hear this word, it comes from the soul of the writer, in this case - Valentin Rasputin. The writer expresses himself, his essence, through this word. Semantic reading of the text, its analysis according to this setting (immanent), is the development in the student of seeing and hearing the Word. By seeing we do not mean simply seeing with the eyes - with the eyes we see almost everything - but seeing with the heart, that is, seeing with the transcendent, the essential. for example, the lexeme eye / eye, which has a place to be in the discourse of v. rasputin " means not only vision, but also symbolizes in the broad sense of the word vision: the ability of a person to know the world around him and his state of mind" [3].

\section{MATERIALS AND METHODS}

As the research material, V. Rasputin's short story "Women's Conversation" is used, which is understood from the perspective of symbols that contribute to the comprehension of the mystery of the text, the formation of key competencies, spiritual and moral values in the younger generation. Such methods as analysis and comparison of texts of artistic works, comprehension of literature as an artistic reality, formation of the spiritual world of a person on this basis, have become leading in the course of this study.

\section{RESULTS}

In the story of $\mathrm{V}$. Rasputin, we feel a philosophical rejection of the destructive power of man on Earth. They are not yet ripe for high spirituality, for beauty and truth, but there are still Saints Natalya in Russia. Rasputin through the image of Natalia shows the eternal desire of man for spirituality, morality-for beauty, that is, for the "world soul", about which so much has been said by Russian philosophers.

The story is constructed in such a way that we see the mental state of the characters. It is shown through motives.

Let's turn to the leading semantic groups of the story.

1. The first is the images of the grandmother's world: "village" - "grandmother" - "truth" - "love" - "gorushka" "house" - " hut " - "chest" - "foundations".

2. The second is the granddaughter of images of the world: "abortion" "company" - "the hound" - "leader".

3. The third is the image of the external world: "the scope" - "electricity".

4. Fourth is images of the world mountain: "star scattering" "light" "sky".

5. Fifth is the image of the frozen earth: "earth."

Further, in order to deepen our acquaintance with literary characters, we used a new angle of view - the vision of the image through symbols, because it seems to us that it allows us to see what is not seen in the usual perception of the text. Students talked about how reading this story caused them a sense of anxiety.

Many researchers are interested in the problem of understanding the essence of artistic images through symbols [8], [9],[10]. We gave students the opportunity to interpret these images through those symbols that, in their opinion, more fully express the essence of these images-characters. "The writer, in order to understand the experiences of these characters, shows them...in moments of emotional outbursts" [11].

Students, based on their vision of images, tried to express the essence of Natalia and Vika through certain symbols. To the question: "What do you think is the symbol of Natalia, Vicky? Why do you see it that way? " - it is equally impossible to answer. Here you need to present your vision of the image, and this appears. The disclosure of the image by means of a symbol has resulted in a lively conversation, the conversation has become debatable, such an approach to analysis (through symbols) gives rise to interest in the writer's Word, teaches us to see the deep layers of the text. The symbol (from the Greek. symbolon-conditional sign - a subject or verbal sign that conditionally expresses the essence of a phenomenon from a certain point of view, which determines the very character, quality of the symbol [11]. students actively participated in the comprehension of images through symbols.

For example, Tatiana's grandmother thinks that she is a star and the boundless sky, and vika is a river making its way, following the star that points the way to the river. as long as there are obstacles in the way of the river ("abortion", "company"), but it will be able to enter the channel that the star points to it; so the stars pointed the way centuries ago, and millennia, and now. And in the future? And in the future... "[12]. 
Darya Vika appears as a small tree with a broken twig, because she has already made a mistake once. Rasputin, telling us about her mistake, notes: "... already baited, already shout guard...". "Until I came to my senses," she was brought to her grandmother in the village. Grandmother (Natalia) she sees in the form of a century-old tree, which, rustling branches, asks Vika: "... heroism is not a sin for you? how do you look at yourself? What a waste I took on myself! "[12].

Artyom, when reading the story, saw a hurricane - this is the company where Vika got. No wonder Rasputin writes: "I contacted the company... spun, spun." rasputin uses this verb twice - this is also not in vain, by this he focuses our attention on the fact that vika's life has turned into a carousel, into a farce that has swallowed her carousel hurricane. And a butterfly falls into this hurricane, its wings are weak, fragile, but the sun has come out - its rays have melted the hurricane force, and the butterfly is saved." Vika, comprehending the question, feels confused; The author briefly but succinctly tells us about this: "Vika stumbled in confusion." She stumbled to get up [12].

Vladimir Vika is associated with a flower, but the flower needs the sun, without it it dies, such a sun for her was her grandmother. I associate it with a ray of sunshine. The sun brings light, grandma also brings the light of her soul to Vika, she says: "Don't be stronger. Need to be more loving. Lovelier than anyone." He gives her his love. Even in the text, I noticed that Natalia gets up and goes to bed with the sun: "Natalia, like an old woman, goes to bed early, following the sun." Following the sun, she herself becomes the sun for Vicki" [12].

Mikhail thinks that Vicki's past is symbolized by the thorns of a rose, and her future is symbolized by her bud. He sees his grandmother in the form of an apple tree with a branching crown and full fruits. The fruits are her wisdom, sedateness, and vika touches them, and is saturated with them: "No, i did not take a dream, i did not take it in any way. Exhausted, the grandmother and granddaughter continued to talk " [12].

Sergey, the image of Vika is seen in the form of an electric light bulb, it is heated and can burn out. This is probably progress that can ruin a life. It is not for nothing that V. Rasputin notes in this story: "The Angara villages were picked up for him (electricity), piled up as it happened, flooded fields and meadows, destroyed the eternal order - all the electricity for him, and they surrounded the Angara villages, letting the wires go far away. and these wires go to the city, and there the light bulbs glow, you see - and they burned out" [12]. He presented his grandmother in the form of a century-old tree, the tree of the family, of life.

Eugene sees his grandmother as the sun, it will never be covered by clouds, I also chose the sun as the symbol of the Wiki, but it is still covered by clouds, but there is hope that the sun of his grandmother will melt these clouds. So it will be, as Vika says: "You're funny, Grandma." She does not just pronounce, but loudly, "with taste", that is, the clouds that cover her sun begin to dissipate" [12].

Andrey thinks that Vika is a river, and Grandma is the sea. The river will flow into the sea, and Vika will gain wisdom. The river becomes the sea, Vika, having acquired the wisdom of Natalia, would also soon be a grandmother and maybe she also held a intimate conversation with his granddaughter, so Rasputin, finishing the story, introduces us to the words of the grandmother, the granddaughter said: "Here you live with me, and give your God the same night to talk with her granddaughter. And she will say to you: you are a funny old woman. Do not refuse: and you will be funny. where to go? Oh, Viktoria, life-save and have mercy...". Grandmother Natalia saves her granddaughter, as the sea saves the Malaya River, keeping its waters in its waters; she has mercy on her, as the sea has mercy on the waters of the malaya river" [12].

Olga Vika presents as a cloudy sky, there are clouds, there is unclean, there is still gray. And Grandma? The wind that drives these clouds away. This is a warm wind, caressing, soft, it is a symbol of Warmth, help, mutual assistance.

Natalia's symbol can also be a mountain, because she, completing the confession, says: "So I'll tell you, granddaughter. I, an ancient old woman, have lived for so many years that I can make two graves. I was exhausted from life. And from here, from my high mountain, it seems to me... " [12].

"Gorushka", which touched the world of stars, that is, the world of the mountain (in dahl, "gorny" is considered as the highest, highest, upper; exalted, in direct and figurative meaning, heavenly, related to the spiritual world), has preserved its purity, prosperity comes from it, whoever touches this gorushka, who tries to climb to its top, for that good days will come, as they began for vika " ... " [12].

The described literary approach has the advantage that it reveals the creative capabilities of students, can not but reveal, because in the process of work they open all three channels of perception: visual, auditory, kinesthetic; they see the text, that is, visually perceive it, read, depict characters in symbols [6], make up a text for them, that 
is, include auditory and kinesthetic channels of perception.

What do we mean by listening? No, not just listening, but responsiveness to the Word, in the end-responsiveness to the world, man, earth, responsiveness to everything that helps to open the soul to a person. Through responsiveness and penetration into the Word, we will come to the idea of the work, to its essence, for which it was written.

First, let's find out again: what is a writer's word? What we see in the text when reading quickly? This is only the surface of the Word. The feelings we experience when reading the text are the Word of the writer, because he passed them through his soul, they carry a part of his soul - therefore it is alive, in them we see the beating of life, the pulsation of feelings, time, space. The space in the story "Women's Conversation" is expanding: first, it is a small point on the planet Earth-the village where Vika was brought, then it is a "blown expanse" not only of the Russian land, but perhaps of the whole world. Rasputin does not give an interpretation to this space, does not indicate its place; then it is the evening, night sky, and, finally, the macrocosm, from which the "starry scattering" appears, which has come to Vika, knocking softly at the window, like a guest.

It is also interesting that the village does not have a name. What does this mean? About many things! Probably, first of all, about the fact that, speaking of one village, Rasputin meant all the villages of Russia, which were "piled up", "flooded", "picked up", as something unnecessary, as an interfering hummock.

What is the time? We have seen the present of Vicki, she "struggles", "re-educates", the past-there is "carousel life, "abortion", "krutovert", retrospectively we see the life of my grandmother: there is freedom and purity. The future? It is given in hints, but still it is present as something inescapable. Rasputin, concluding the text, writes: ... the sky, unfolding, everything played... foreshadowing tomorrow's inevitability" [12].

And all this time, and the space is transferred with the help of Words. For what? so that we can get into the writer's artistic world, understand the problems raised, and perceive them. With the help of the Word, the place of action is also conveyed - in the present for Vika-it is a village, in the past-a city, in the future... she must make a choice. rasputin does not answer this question, he gives us the right to speculate without him, but with the help of his word. for natalia, the past, present, and future are a village-a sacred place.

Students talk about the characters not according to a given plan, but in their own way, while not leaving the artistic world of this particular work. this approach to the analysis of the work is also appropriate, it is complete and complete, extremely concise, concrete.

Thus, we see a conflict between the external world, which is based on dislike, and the world of the granddaughter, which is based on instability; thanks to instability, the external world almost destroyed Vika. What is the way out of this conflict proposed by V. Rasputin? To resist this world (blown), you need to have foundations, which is what Vika gets from Natalia.

\section{CONCLUSION}

In the art world of this story distinct and almost no action, except for action "star placers", which beats against the window, asleep, shivering", Vic, apart from the action of asking questions to grandma, wanting to know the moral and philosophical laws of existence. This construction of the story works on the main theme of the work: the image of the spiritual awakening of the granddaughter, one of the inhabitants of the Earth, which is now in a "daze".

In The Mysticism of Sound, Hazrat Inayat Khan writes: "There are three perceptions. One way of perception belongs to the surface of the mind, which is thought. Thoughts appear to our mind as having different shapes, lines, and colors. But there is a third way of perception, which is not even through the senses, and which can be called spiritual language. It comes from the greatest depths of the heart. It is the voice of the spirit. It belongs to the definite and clear. And this perception can be called intuition - there is no better name for it. in order to study life in its entirety, these three types of perception must be developed. Only then can a person know life in its entirety; and only by studying it comprehensively can a person form a judgment about it" [13].

Thus, students through creative activity-understanding the symbols of the text-were able to extract the" hidden " beauty in the world, to remain in the position of a citizen of the world, they had a lively interest in being, the inner world of man, nature, the phenomenon of creativity, the place of the artist and man in this world. understanding the depths of discourse provides the key to understanding the leading goal of life self-realization. as a result, they come to the denial of the way of life that humiliates and destroys a person 
as an individual, as a carrier of the whole world, the universe. they learn the basic life behavior: restraint, concentration, maximum tension of spiritual, internal forces, life support, resilience, striving for the ideal.

\section{REFERENCE LIST}

1. Ermakova, G. A., Yakimova, N. I., Sorokina, O. V., Savirova, M. P. (2016). Formation of spiritual needs in a multicultural environment (education of the soul as a strategic project) / / Problems of modern pedagogical education. No. 51-6. pp. 122-131.

2. Savirova, M. P. (2016). Researchers on the features of the adventurous plot in the adventure genres of Chuvash literature / / Problems of Mari and Comparative Philology. Of the "Mari state University". Yoshkar-Ola, pp. 205-206.

3. Yakimova, N. I. (2006). Phraseological units with the component KUÇ / KUZ / kuş / GÖZ "EYES" in the Chuvash, Tatar, Bashkir and Turkish languages. Bulletin of the Chuvash University, No. 7, pp. 160166.

4. Ermakova, G. A. (2015). The role of binary oppositions in the collection of S. Azamat "Trickle drops". Bulletin of the Chuvash University. No. 2. pp. 145-152.

5. Ermakova, G. A. Yakimova, N. I. (2015). The art world GN Aigi as a representation of the worldview of the Chuvash ethnic group // culture of peoples of the Volga-Kama polyethnic region in the paradigm of modernity: collection of articles of Yoshkar-Ola. S. 83-87.

6. Savirova, M. P. (2015). Vital material and hero of adventurous and adventurous literature of the peoples of the Ural-Volga region / / Philological Sciences. Questions of theory and practice. No. 6-2 (48). pp. 148151.

7. Yakimova, N. I. (2015). National and cultural features of phraseological units of related languages / / In the collection: Problems of culture in modern education: global, national, regional and ethnic Collection of scientific articles. Edited by G. L. Nikonova, A.V. Nikitina, pp. 188-192.

8. Ermakova, G. A. (2015). The branch of the Tree of life has broken (N. Izhendey's poem "The Voice of the Unborn Child" as a space for presenting the global problem of humanity) / / Problems of culture in modern education: global, national, regional and ethnic Collection of scientific articles. Edited by G. L. Nikonova, A.V. Nikitina, pp. 54-57.

9. Savirova, M. P. (2016). The formation of the adventure genre in a national literature // Almatinskie reading. Proceedings of the $X$ International Scientific and Practical Conference, pp. 56-58.

10. Sorokina, O. V., Yakimova, N. I. (2016). Paremia with a modality component in the Chuvash and Turkish languages. Questions of theory and practice. No. 12-4 (66). pp. 182-184.

11. Savirova, M. P. (2018). The phenomenon of artistic intrigue in Chuvash adventure prose / / Bulletin of the Mari State University. Vol. 12. No. 1 (29). pp. 149-154.

12. Rasputin, V. G. (1995). Women's conversation. Moscow, No. 7, pp. 3-10.

13. Hazrat, Inayat Khan (1998). Mysticism of sound. M.: Sphere. 198 p. 